\title{
Potential lineage transmission within the active microbiota of the eggs and the nauplii of the shrimp Litopenaeus stylirostris: possible influence of the rearing water and more
}

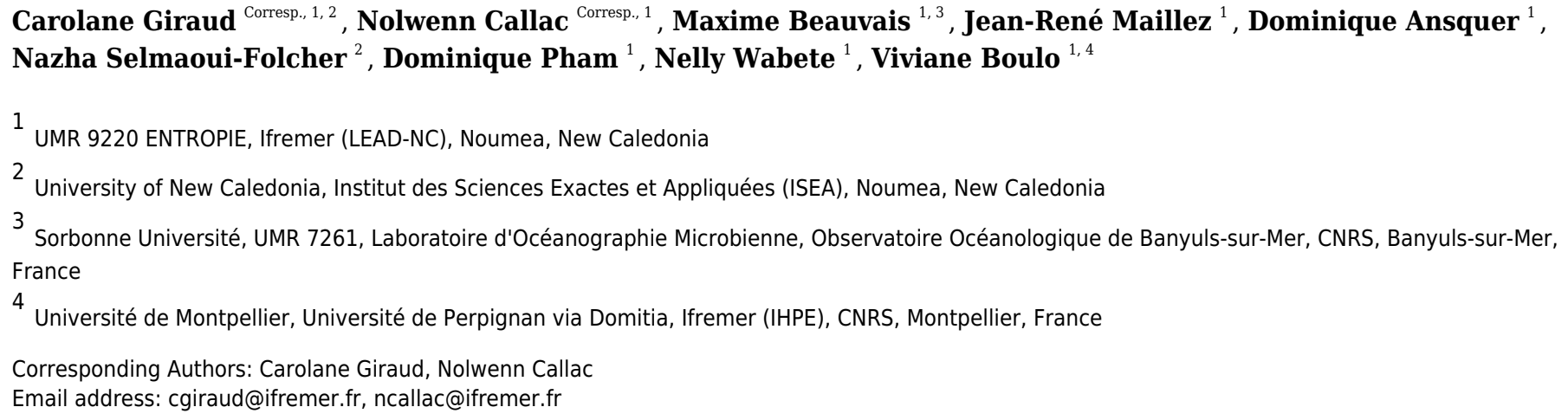

Background. Microbial communities associated with animals are known to be key elements in the development of their hosts. In marine environments, these communities are largely under the influence of the surrounding water. In aquaculture, understanding the interactions existing between the microbiotas of farmed species and their rearing environment could help establish precise bacterial management. Method. In light of these facts, we studied the active microbial communities associated with the eggs and the nauplii of the Pacific blue shrimp (Litopenaeus stylirostris) and their rearing water. All samples were collected in September 2018, November 2018 and February 2019. After RNA extractions, 2 distinct Illumina HiSeq sequencings were performed. Due to different sequencing depths and in order to compare samples, data were normalized using the Count Per Million method. Results. We found a core microbiota made of taxa related to Aestuariibacter, Alteromonas, Vibrio, SAR11, HIMB11, AEGEAN 169 marine group and Candidatus Endobugula associated with all the samples indicating that these bacterial communities could be transferred from the water to the animals. We also highlighted specific bacterial taxa in the eggs and the nauplii affiliated to Pseudomonas, Corynebacterium, Acinetobacter, Labrenzia, Rothia, Thalassolituus, Marinobacter, Aureispira, Oleiphilus, Profundimonas and Marinobacterium genera suggesting a possible prokaryotic vertical transmission from the breeders to their offspring. This study is the first to focus on the active microbiota associated with early developmental stages of a farmed shrimp species and could serve as a basis to comprehend the microbial interactions involved throughout the whole rearing process. 
1 Potential lineage transmission within the active microbiota

2 of the eggs and the nauplii of the shrimp Litopenaeus

3 stylirostris: possible influence of the rearing water and more

4

5

6

7

8

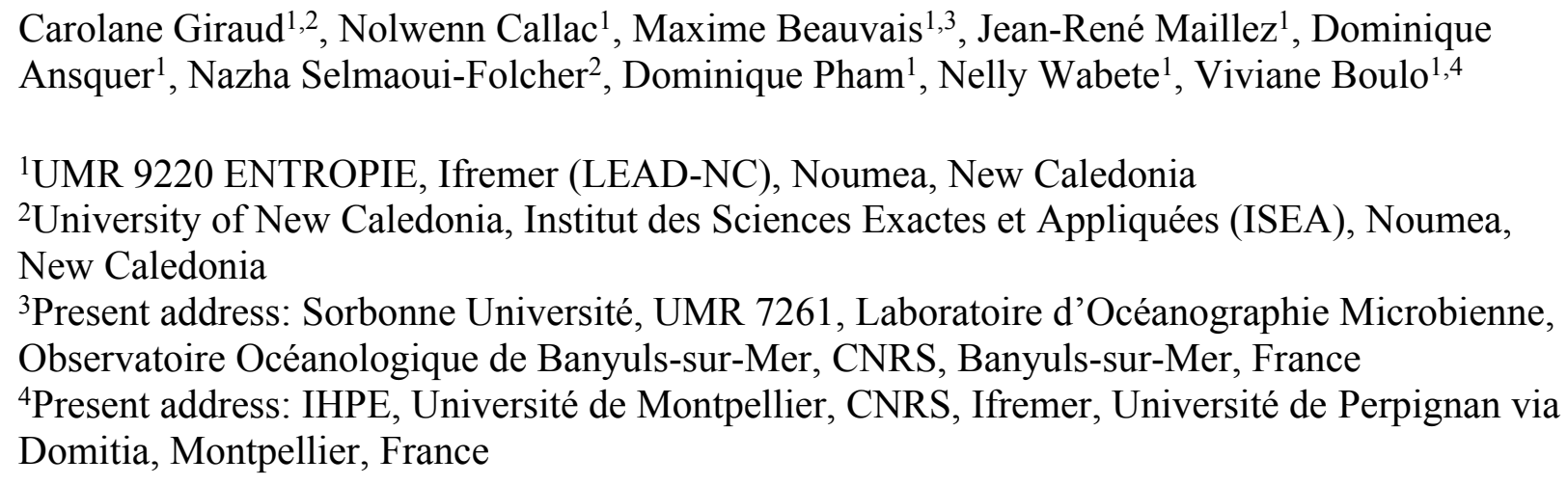

\section{Abstract}

Background. Microbial communities associated with animals are known to be key elements in the development of their hosts. In marine environments, these communities are largely under the influence of the surrounding water. In aquaculture, understanding the interactions existing between the microbiotas of farmed species and their rearing environment could help establish precise bacterial management.

Method. In light of these facts, we studied the active microbial communities associated with the eggs and the nauplii of the Pacific blue shrimp (Litopenaeus stylirostris) and their rearing water. All samples were collected in September 2018, November 2018 and February 2019. After RNA extractions, 2 distinct Illumina HiSeq sequencings were performed. Due to different sequencing depths and in order to compare samples, data were normalized using the Count Per Million method.

Results. We found a core microbiota made of taxa related to Aestuariibacter, Alteromonas, Vibrio, SAR1 1, HIMB11, AEGEAN 169 marine group and Candidatus Endobugula associated with all the samples indicating that these bacterial communities could be transferred from the water to the animals. We also highlighted specific bacterial taxa in the eggs and the nauplii affiliated to Pseudomonas, Corynebacterium, Acinetobacter, Labrenzia, Rothia, Thalassolituus, Marinobacter, Aureispira, Oleiphilus, Profundimonas and Marinobacterium genera suggesting a possible prokaryotic vertical transmission from the breeders to their offspring. This study is the first to focus on the active microbiota associated with early developmental stages of a farmed shrimp species and could serve as a basis to comprehend the microbial interactions involved throughout the whole rearing process.

\section{Introduction}


45 It is widely recognized that microorganisms, and more particularly prokaryotes, colonize all

46 types of habitats (Whitman, Coleman \& Wiebe, 1998; Mora et al., 2011) and are involved in

47 crucial reactions in various biogeochemical cycles (Falkowski et al., 2008). Microorganisms

48 have also been extensively studied for their implication in the human microbiota (Huttenhower et

49 al., 2012) and thus for their involvement in health, development and behavior (Cho \& Blaser,

50 2012; Moloney et al. 2014). Marine animals also host essential microbial communities associated

51 with their skin (ex. mammals, fishes) or their exoskeleton (crustaceans) as well as their digestive

52 and respiratory systems (Apprill, 2017). These communities are largely influenced by the marine

53

54 environment which is colonized by all types of microorganisms (Sehnal et al., 2021). More and more studies suggest that comprehending the interactions existing among marine animals, their microbiota and their aquatic environment could help understand the response of these animals to climate change and pollution and could also help improve management of farmed species (Egan \& Gardiner, 2016; Sehnal et al., 2021).

In New Caledonia, the Pacific blue shrimp (Litopenaeus stylirostris) is a valuable farmed species and represents an economical challenge for the territory (Beliaeff et al., 2009). Indeed, since 1970, the sector has become the island's leading food-processing exporter (Rural Agency of New Caledonia) with a semi-intensive annual production of 1500 tons. Unfortunately, the production has been declining due to seasonal vibriosis touching adult individuals (Goarant et al., 1999, 2006) and to larval mortalities that have not yet been explained. Knowing that natural seawater is used during the rearing process and that the New Caledonian lagoon has been more and more exposed to anthropic pressures over the years, hypothesis have been made regarding the water quality in order to explain these early mortalities. Thus, understanding the interactions that exist between the microbial communities associated with the rearing water and the different larval stages of L. stylirostris could help lead to precise bacterial management during shrimp farming. As a first step in understanding the microbiota of L. stylirostris, we studied the active microbial communities associated with the eggs, the first larval stages (nauplii) and the rearing water. Samples were collected at 3 different times in September 2018 (cool season), November 2018 (transitional season) and February 2019 (warm season). Bacterial lineages affiliated to Aestuariibacter, Alteromonas, Vibrio, SAR11, HIMB11, AEGEAN 169 marine group and Candidatus Endobugula were found in all the samples but in different proportions suggesting that some bacterial communities in the rearing environment could potentially colonize the eggs and the nauplii. We also found specific taxa related to Pseudomonas, Corynebacterium, Acinetobacter, Labrenzia, Rothia, Thalassolituus, Marinobacter, Aureispira, Oleiphilus, Profundimonas and Marinobacterium genera in the eggs and the nauplii that were not found in the water samples and could have been vertically transmitted from the breeders.

\section{Materials \& Methods}

82 Study design and sample collection

83 Eggs and nauplii of L. stylirostris were supplied by the experimental shrimp hatchery located at 84 the Saint Vincent Bay (Ifremer, Boulouparis, New Caledonia) in September 2018 (M1), 85 November 2018 (M3) and February 2019 (M4). For all experiments, breeders were reared in 86 maturation tanks according to the method described in Pham et al. 2012 (Pham et al., 2012).

87 Tanks in the maturation and in the hatchery were filled with natural seawater from the Saint 88 Vincent Bay. Natural seawater was pumped through a $1 \mathrm{~cm}$ pore size strainer in a primary 89 reservoir (ResI), was then filtered on a $10 \mu \mathrm{m}$ pore size filter and stored in a secondary reservoir 90 (ResII). In the secondary reservoir, seawater was circulated for 3 days, through a loop composed 
91 of 1 and $5 \mu \mathrm{m}$ pore size filters and a skimmer. Seawater was briefly passed through a UV

92 chamber before filling the hatchery tanks. In each tank, $5 \mathrm{~g} \cdot \mathrm{m}^{-3}$ of ethylenediaminetetraacetic

93 acid (EDTA) were finally added (Fig. S1). Seawater from the primary reservoir was sampled 5

94 days before artificial inseminations. Seawater from the secondary reservoir was sampled after

95 filtration and skimmer treatments, on the day the eggs were collected. For each experiment, 1L

96 of seawater from the primary and the secondary reservoirs were collected and were filtered on a

$970.2 \mu \mathrm{m}$ pore size filter (S-PAK membrane filter, Millipore). Filters were kept for RNA extractions

98 and were stored at $-80^{\circ} \mathrm{C}$; filtrates were used, within the 2 hours of sampling, to analyse the

99 Colored Dissolved Organic Matter (CDOM) as described in Helms et al. 2009 and Sadeghi-

100 Nassaj et al. 2018 (Helms et al., 2009; Sadeghi-Nassaj et al., 2018).

101 After artificial insemination and spawning, around a hundred eggs were collected in a $2 \mathrm{ml}$ sterile

102 microtube using sterilized pliers. The following day, before transfer into rearing tanks for larval

103 rearing, around a hundred nauplii were sampled in the same way as the eggs using sterilized

104 pliers. All egg and nauplius samples were stored at $-80^{\circ} \mathrm{C}$ until further RNA extractions. For the

105 M4 experiment, eggs and nauplii were sampled in replicates (M4_Egg1, M4_Egg2, M4_Nii1,

106 M4_Nii2) whereas unique egg and nauplius samples were collected during the M1 and the M3

107 experiments.

108

109

RNA extractions and sequencing

110 Due to different sample types, RNA extractions were performed using the RNeasy PowerWater

111 kit (Qiagen) for the filters, and using the RNeasy minikit (Qiagen) for the eggs and the nauplii.

112 Total RNAs were reverse-transcripted into complementary DNA (cDNA) by adding 200ng of

113 RNAs to a reaction mix (buffer $5 \mathrm{X}$, dNTP $10 \mathrm{mM}$, random hexamers $50 \mu \mathrm{M}$, reverse transcriptase

114 M-MLV (PROMEGA) 200u. $\mu 1^{-1}$, RNAse/DNAse free water). Reverse-transcription was

115 performed in a thermocycler (VerityTM, Applied Biosystems) during $10 \mathrm{~min}$ at $25^{\circ} \mathrm{C}, 2 \mathrm{~h}$ at $42^{\circ} \mathrm{C}$

116 and $5 \mathrm{~min}$ at $85^{\circ} \mathrm{C}$.

117 All cDNAs were sent to MrDNA (Shallowater, TX, United States) in order to amplify and

118 sequence the V4 region of the 16S rRNA gene using the 515F/806R primers (Caporaso et al.,

119 2011). A HiSeq Illumina sequencing was conducted using a 2x300pb paired-end run.

120 Due to different sampling times, two distinct sequencings were performed. All samples from the

121 M1 and the M3 (M3a, first sequencing) experiments were sequenced in February 2019 with an

122 average sequencing depth of 20k raw reads per samples. All samples from the M4 experiment as

123 well as the egg and the nauplius samples from the M3 experiment (M3b, second sequencing)

124 were sequenced in November 2019 with an average sequencing depth of 50k raw reads per

125 sample.

126

127

128

129

Microbiota analysis

Raw sequences were demultiplexed using the MrDNA tool fastqSplitter

130 (https://www.mrdnalab.com/mrdnafreesoftware/fastq-splitter.html). Demultiplexed sequences

131 were treated using the DADA2 (Callahan et al., 2016) package available in the RStudio software

132

133

134

135 (RStudio Team, 2020). Briefly, sequences were filtered using a maximum expected error of 2. Filtered sequences were used to estimate error rates and dereplication. Dereplicated samples and error rates were implemented in the DADA2 error model in order to correct sequencing errors and construct Amplicon Sequence Variants (ASVs) as described in Callahan et al., 2016 (Callahan et al., 2016). Paired-end reads were merged and chimeras were removed using the 
136 "per-sample" method. Taxonomy was finally assigned using the Silva 138 database (Quast et al., 137 2013).

138 Data were normalized with the Counts Per Million (CPM) method using the cpm function 139 available in the edgeR package under RStudio (Robinson, McCarthy \& Smyth, 2009). All 140 libraries were normalized to $1,000,000$ reads prior to microbiota analysis. A dendrogram based 141 on a Bray-Curtis dissimilarity matrix and Ward method was obtained using the vegan, ggplot2, 142 dplyr and dendextend packages in RStudio (Galili, 2015; Oksanen et al., 2020; Wickham, 2016;

143 Wickham et al., 2021). Histogram tables were obtained using the dplyr package in RStudio

144 Wickham et al., 2021). Venn diagrams were made using the open-source component for web

145 environment jvenn (http://jvenn.toulouse.inra.fr/app/example.html) (Bardou et al., 2014).

146 All the 16S rRNA data are available in the NCBI SRA repository (Submission ID SUB9828953, 147 BioProject ID PRJNA736535).

148

\section{Results}

150 CDOM (Colored Dissolved Organic Matter) measurements

151 Two parameters were analyzed during CDOM measurements of the water samples: the 152 absorption coefficient at $325 \mathrm{~nm}\left(\mathrm{a} \lambda_{325}\right)$ and the ratio of the spectral slopes (SR) $\left(\left(\mathrm{a} \lambda_{275-295}\right) /(\right.$

$\left.153 \mathrm{a} \lambda_{350-400}\right)$ ) which are respectively used as a proxy for CDOM concentration and as an indicator of 154 the molecular weight of Dissolved Organic Matter (DOM) (Sadeghi-Nassaj et al., 2018). The 155 a $\lambda 325$ values of all the reservoir samples ranged from 0.8 to $1.1 \mathrm{~m}^{-1}$. For all experiments, the SR 156 values varied from 5.98 to 7.67 in the primary reservoirs (ResI) and from 4.79 to 8.12 in the 157 secondary reservoirs (ResII). For the M1 experiment, the SR value was higher in the ResI sample 158 (7.06) than in the ResII sample (4.79). For the M3 and the M4 experiments, trends were inverted

159 (Table 1) as SR values respectively equaled 7.67 and 5.98 in the primary reservoirs; and 8.12 and 1606.27 in the secondary reservoirs.

161

162

163

Microbial diversity

164

A total of 2,987,759 sequences were obtained from the Illumina sequencings of all samples (M1, M3a, M3b and M4). Sequences were clustered into 4950 distinct ASVs. The smallest and largest libraries were respectively composed of 15399 and 554056 reads and corresponded to the M3a_Egg and M3b_Nii samples. All libraries were normalized to 1,000,000 reads using the CPM method.

168 Hierarchical clustering based on Bray-Curtis similarity separated the samples into 2 distinct groups (Fig. 1A). The cluster 1 gathered all the water samples while the cluster 2 contained all the egg and the nauplius samples. All the water samples from the primary reservoirs clustered together with the ResII sample from the M1 experiment. The water samples from the other secondary reservoirs (M3a and M4) clustered separately. Eggs and nauplii sampled during the M3 experiment and sequenced twice formed a unique subgroup while the egg and the nauplius samples from the M1 and M4 experiments clustered together.

175 For all samples, 11 dominant classes were highlighted (Fig. 1B). Gammaproteobacteria (45\% of

176 the total ASV relative abundance) and Alphaproteobacteria (19\%) were the most abundant

177 classes followed by Bacteroidia (10\%) and Verrucomicrobiae (5\%). Acidimicrobiia,

178 Planctomycetes and Cyanobacteriia each represented 3\% of the ASVs table. Water samples from

179 all the primary reservoirs showed consistent total bacterial compositions with five predominant

180 classes: Alphaproteobacteria, Gammaproteobacteria, Acidimicrobiia, Cyanobacteriia and

181 Bacteroidia. The bacterial diversity of the M1_ResII sample was very similar to the one of the 
182 primary reservoirs. The other water samples from the secondary reservoirs also contained

183 Alphaproteobacteria and Gammaproteobacteria but Planctomycetes dominated the M3_ResII

184 sample while the M4_ResII sample was mainly composed of Verrucomicrobiae. Global bacterial

185 communities associated with the egg and the nauplius samples majorly displayed

186 Gammaproteobacteria, Alphaproteobacteria and Bacteroidia (over 70\% of the total ASV relative

187 abundance). Eggs were also composed of Fusobacteriia, especially for the M1 experiment, while

188 nauplii were partly composed of Desulfuromonadia.

189

190

191

Specific and shared ASVs among samples

In order to highlight specific and shared ASVs among all samples, we constructed several Venn

192

193

194

diagrams. First, four distinct Venn diagrams were built to find common ASVs among all experiments for each sample type (Fig. S2). A total of 330 ASVs were shared among all the primary reservoir samples (Fig. S2A). All the secondary reservoir samples owned 215 ASVs

195

196 (Fig. S2B) whereas the egg (Fig. S2C) and the nauplius (Fig. S2D) samples respectively shared 270 and 259 ASVs. We used these four ASV lists to build a final Venn diagram allowing us to highlight 623 distinct ASVs; specific and common among the compartments (Fig. 2). A total of 257 ASVs were uniquely found in the water samples (Fig. 2A). The primary and the secondary reservoirs respectively showed 145 and 33 specific ASVs while they shared 79 ASVs. All the

200

201

202

203

204

205

206

207

208

209

210

211

212

213

214 considered samples shared 62 ASVs (Fig. 2B). In the same way as the water samples, 233 ASVs were only found in the egg and the nauplius samples (Fig. 2C); 88 ASVs were specific to the egg samples while 80 ASVs were uniquely highlighted in the nauplius samples. The eggs and the nauplii shared 65 ASVs that were not identified in the water samples.

Specific and shared bacterial communities among samples

Based on the Venn diagram (Fig. 2), we analyzed the relative abundance of each subset of ASVs selected above by constructing $100 \%$ stacked histograms. The water samples showed specific ASVs (Fig. 3A). The microbiota specifically associated with the primary reservoirs showed 4 dominant groups which accounted for $30 \%$ of the total relative abundance (Fig. 3B): OM60 Clade, Sva0996 marine group, MB11c04 marine group and NS5 marine group. One ASV was not affiliated to the genus level (Nitrincolaceae) and represented $20 \%$ of the total relative abundance. Candidatus Actinomarina, Synechococcus and SAR1 16 Clade were shared between the primary and secondary reservoirs and accounted for $49 \%$ of the total relative abundance (Fig. 3C). The secondary reservoir samples highlighted a very specific and highly represented ASV affiliated to Pedosphaeraceae family which accounted for $80 \%$ of the total abundance (Fig. 3D). A total of 62 ASVs were shared among all the samples (Fig. 4A). In this microbiota, 15 genera and 4 ASVs which were not affiliated to the genus level were highlighted. Even though all these bacterial lineages were found in all samples, their total relative abundance varied. Indeed, the ResI samples were dominated ( $60 \%$ of the total relative abundance) by SAR11 Clade Ia, HIMB 11 and by an ASV affiliated to the AEGEAN 169 marine group (Fig. 4B). The secondary reservoirs showed higher abundances for 3 ASVs which were affiliated to Candidatus Endobugula, Gimesiaceae and NRL2 (Fig. 4C). In both egg (Fig. 4D) and nauplius (Fig. 4E) samples, Aestauriibacter, Alteromonas and Vibrio genera represented over $50 \%$ of the total relative abundance.

Bacterial compositions of communities specifically associated with the egg and the nauplius samples were evaluated alongside with transmitted ASVs between the two sample types (Fig. $5 \mathrm{~A})$. In the egg samples, 21 bacterial lineages accounted for more than $80 \%$ of the total relative 
228

229

230

231

232

233

234

235

236

237

238

239

240

241

242

243

244

245

246

247

248

249

250

251

252

253

254

255

256

257

258

259

260

261

262

263

264

265

266

267

268

269

270

271

272

273

abundance (Fig. 5B). Pseudomonas and Corynebacterium each had a relative abundance of $18 \%$. Acinetobacter represented $8 \%$ of the total relative abundance while Labrenzia and Rothia each accounted for $6 \%$. These five genera alone represented more than $55 \%$ of the total relative abundance among the bacterial communities specifically associated with the egg samples. Some ASVs seemed transmitted from the eggs to the nauplii (Fig. 5C). Among those ASVs, 21 bacterial lineages were highlighted and accounted for $90 \%$ of the total relative abundance. The most abundant genera were Thalassolituus (20\%), Vibrio (18\%), Marinobacter (5\%), Aureispira $(5 \%)$ and Oleiphilus (4\%). One ASV accounted for $5 \%$ of the total relative abundance but could not be affiliated to the genus level (MBAE14 Order). Specific ASVs were also found in all the nauplius samples; 17 bacterial lineages were highlighted and represented $85 \%$ of the total relative abundance (Fig. 5D). Profundimonas and Marinobacterium respectively represented $15 \%$ and $8 \%$ of the total relative abundance. Two ASVs accounted for $28 \%$ of the abundance and were affiliated to SGC AAA286 E23 and Bacteroidia (unknown order).

\section{Discussion}

Dealing with sequencing depths

Due to different sampling times and sequencing runs, the choice of bioinformatic techniques for data analysis was very important. Thus, we considered and compared several methods to cluster sequences and to normalize the considered dataset. During the last decade, two ways have been used to cluster sequencing reads: the Operational Taxonomic Units (OTUs) or the ASVs. OTUs cluster sequences which are identical up to a fixed similarity threshold (usually 97\%) while ASVs regroup identical sequences after a sequencing error correction step (Callahan et al., 2016). Comparing the 2 methods, it appears that biological conclusions are very similar (Allali et al., 2017; Glassman \& Martiny, 2018). However, ASVs are advised for improved reproducibility, comparison across studies, meta-analysis and nucleotide-level resolution (Callahan, McMurdie \& Holmes, 2017; Porter \& Hajibabeai, 2020). As the samples considered in our study had been collected during 3 different experiments and were sequenced separately, we chose to analyze sequencing data using the ASV method implemented in the DADA2 package under RStudio (Callahan et al., 2016) in order to enable comparison among samples. After sequencing data analysis, library sizes among samples varied from 15399 to 554056 reads because of different sequencing depths. As a consequence, hierarchical clustering based on BrayCurtis dissimilarity of non-normalized data showed a clear sequencing depth effect as samples sequenced together gathered together (Fig. S3). In order to compare samples, data needed to be normalized. The rarefaction method has been extensively used to normalize metabarcoding data but it leads to non-reproducible tables and randomly suppresses OTUs or ASVs (McMurdie \& Holmes, 2014). The edgeR and DESeq methods have been advised but involve the use of logarithms and do not handle well null values (Weiss et al., 2017) which were quite abundant in our dataset. A recent study showed that simpler methods lead to satisfying normalizations (Bushel et al., 2020). Thus, we chose the Count Per Million (CPM) method which enabled hierarchical clustering of the samples according to their bacterial compositions rather than their sequencing runs.

Chemicophysical and microbial quality of the water samples

CDOM concentrations were constant throughout all the water samples. However, SR values decreased from the primary to the secondary reservoirs during the M1 experiment and opposite tendencies were observed during the M3 and M4 experiments (Table 1). Shifts in SR can be 
274 correlated to molecular weight and composition modifications of the dissolved organic matter

275 (Helms et al., 2009) suggesting that such changes occurred in the reservoirs and were of different

276 natures during the M1 experiment compared to the M3 and M4 experiments. Overall, all the

277 water samples showed a large abundance of Gammaproteobacteria and Alphaproteobacteria (Fig.

278 1B) which are respectively dominant classes in pelagic and benthic marine environments (Zinger

279 et al., 2011). The primary reservoirs and the M1_ResII sample were also majorly composed of

280 Acidimicrobiia, Cyanobacteriia and Bacteroidia, 3 classes previously identified in pelagic

281 environments and marine ecosystems (Giovannoni \& Stingl, 2005; Zinger et al., 2011). The M3

282 and M4 secondary reservoirs respectively displayed important abundances of Planctomycetes

283 and Verrucomicrobiae which have been found in soil, freshwater (Australian dam, Hungarian

284 pond) and seawater (the Californian Current) ( Fuerst, 1995; Freitas et al., 2012). CDOM

285 measurements and bacterial compositions in water are known to be correlated factors (Judd et al.,

286 2006). A change in the CDOM measurements can result in a change of the microbiota and vice

287 versa. Thus, it is quite difficult to distinguish the cause and the consequence. However, both

288

289

290

291

292

293

294

295

296

297

298

299

300

301

302

303

304

305

306

307

308

309

310

311

312

313

314

315

316

317

318 Putative factors influencing the microbial communities associated with the eggs and the nauplii

319 these factors can also be influenced by seasonal variations (Osterholz et al., 2018). As our samplings occurred between September 2018 and February 2019, seasonal variations could explain the differences observed in our samples in terms of SR tendencies and differential bacterial communities. However, as the primary reservoirs were quite similar and were a closer reflection of the natural conditions, the differences observed in the secondary reservoirs may also be explained by other factors. As we performed RNA extractions, we studied active prokaryotic communities (Blazewicz et al., 2013). We can thus hypothesize that differences in bacterial compositions, and therefore in CDOM profiles, may be due to different active microorganisms throughout the water treatments.

Specific bacterial communities associated with the primary reservoir samples were dominated by 4 marine groups (OM60 Clade, Sva0996, MB11c04 and NS5) (Fig. 3B). They have been identified as crucial communities in the marine environment and have been found in various ecosystems ranging from marine sediments and surface seawaters to polar and coastal marine ecosystems ( Suzuki et al., 2001; J. C. Cho et al., 2007; Gómez-Pereira et al., 2010; Orsi et al., 2016). Specific ASVs were common to the primary and the secondary reservoirs (Fig. 3C) and were dominated by members of Candidatus Actinomarina, Synechococcus and SAR116. These bacterial groups are ubiquitous in marine ecosystems and are known as or linked to primary producers (Britschgi \& Giovannoni, 1991; Partensky \& Vaulot, 1999; Ghai et al., 2013) . This could suggest that these communities are present in the Saint Vincent Bay and persist throughout the reservoirs. However, specific ASVs associated with the secondary reservoirs (Fig. 3D) were largely dominated by an ASV affiliated to the Pedosphaeraceae family (Verrucomicrobiae class) suggesting that the water treatments between the primary and secondary reservoirs could select some bacterial communities. This has already been noticed by Vadstein et al. who showed that UV treatment of rearing water induced selection of fast-growing and opportunistic bacteria (Vadstein et al., 2018). The water samples considered in this study were collected before addition of ethylenediaminetetraacetic acid (EDTA) in the hatching tanks. To our knowledge, there is very few information about the effect of this metal chelator on active microbial communities in water. Thus, further investigations will be necessary to evaluate the role of EDTA on the microbiotas associated with the rearing water and the animals in shrimp hatcheries. of L. stylirsotris 
320 In the egg and the nauplius samples, Gammaproteobacteria, Alphaproteobacteria and Bacteroidia 321 dominated (Fig. 1B). These classes have been identified in larvae of the Pacific white shrimp

322 (Litopenaeus vannamei) at early developmental stage (Pangastuti et al., 2009; Zheng et al., 2017)

323 but also in the intestines of adult black tiger shrimps (Penaeus monodon) (Rungrassamee et al.,

324 2013). Eggs showed members of the Fusobacteriia class which have also been identified in adult

325 shrimps (Rungrassamee et al., 2016; Zeng et al., 2017) indicating a possible preservation of

326 bacterial communities throughout the whole lifecycle of shrimps. Overall, all the considered

327 samples displayed similar bacterial compositions suggesting that the microbiotas of the eggs and

328 the nauplii could also be influenced by their rearing environments (Fig. 1B). A total of 62 ASVs

329 were shared among all compartments (Fig. 2B) and were considered to be the core microbiota of

330 all our samples (Shade \& Handelsman, 2012). Aesuariibacter, Alteromonas and Vibrio, which

331 are ubiquitous genera in marine (Chan et al., 1978; Yi, Bae \& Chun, 2004; Farmer et al., 2015),

332 were present in all the samples but dominated the eggs and the nauplii (Fig. 4D and 4E). Bacteria

333 affiliated to Alteromonas and Vibrio produce extracellular hydrolases involved in the

334 biodegradation of various organic carbon sources (Chan et al., 1978; Farmer et al., 2015).

335 Vibrios are also known to express genes involved in the metabolic degradation of chitin (Hunt et

336 al., 2008), an important component of the exoskeleton of the nauplii. As mouth opening occurs

337 after the nauplius stage in Litopenaeus shrimps (Wang et al., 2020), the vitellus is the only

338 nutrient and energy resource until the zoae stage (Harrison, 1997). Thus, these bacterial

339 communities may be less represented in water and could find favorable organic carbon sources

340 and growth conditions on the external layer of the eggs and the exoskeleton of the nauplii

341 (Hansen \& Olafsen, 1999). Indeed, the microorganisms that were more represented in the water

342 samples were completely different and belonged to very common marine groups (HIMB11,

343 SAR11, AEGEAN) ( Morris et al., 2002; Durham et al., 2014; Cram et al., 2015). As it has been

344 shown for other animal species (brown trout, coho salmon), the total microbiota of the eggs and

345 the nauplii may embrace the epibiota at the surface but also the endobiota (Nyholm, 2020).

346

347

348

349

350

351

352

353

354

355

356

357

358

359

360

361

362

363

364

365

Bacterial communities specifically associated with the egg samples (Fig. 5B) were dominated by Pseudomonas, Acinetobacter and Labrenzia, 3 genera found in marine environments (Fournier \& Richet, 2006; Palleroni, 2015; Raj Sharma et al., 2019) and which had already been studied during the development of L. vannamei and P. monodon (Rungrassamee et al., 2013; Wang et al., 2020). The egg samples were also composed of Corynebacterium, a genera isolated from coral mucus (Ben-Dov et al., 2009). The eggs finally displayed large abundances of Rothia, usually found in human mouth cavities (Tsuzukibashi et al., 2017) and considered as sample contaminants in vent shrimps (Methou et al., 2019). Like Alteromonas and Vibrios,

Pseudomonas and Corynebacterium are able to degrade different organic carbon sources using extracellular enzymes and could thus find optimal growth conditions with shrimp eggs and the nauplii explaining why they were so abundant among these samples (Palleroni, 2015; Tsuzukibashi et al., 2017). Concerning Labrenzia, they are known to produce labrenzbactin, a catecholate-containing siderophore which demonstrates an antimicrobial activity against Micrococcus luteus (Raj Sharma et al., 2019). Interestingly, M. luteus and Rothia are both affiliated to the Micrococcaceae family and have been respectively identified in the hepatopancreas of healthy adult shrimps (L. vannamei) and in the eggs of vent shrimps (DuránAvelar et al., 2018 ; Methou et al., 2019). This suggests that Rothia, may not be a sample contaminant as previously stated by Methou et al., 2019 (Methou et al., 2019). Further investigations will be necessary in order to determine if this genus is part of the core microbiota

Peer] reviewing PDF | (2021:07:63647:1:1:NEW 31 Aug 2021) 
366 of the eggs of L. stylirostris or not. Either way, all the ASVs that were not identified in the water

367

368

369

370

371

372

373

374

375

376

377

378

379

380

381

382

383

384

385

386

387

388

389

390

391

392

393

394

395

396

397

398

399

400

401

402

403

404

405

406

407

408

409

410

411 environment could have been potentially vertically transmitted from the breeders. Vertical transmission has also been suggested in hydrothermal shrimps where the eggs were associated with specific bacterial communities that were not found in the environment (Methou et al., 2019). Intraovum vertical transmission has already been highlighted in farmed fish eggs, accounting for $20 \%$ of the total bacterial relative abundance in eggs (Hansen \& Olafsen, 1999). Furthermore, a vertical transmission of 2 virus types has been proved using molecular techniques in the redclaw crayfish cultured in Australia (Jaroenram et al., 2021). Thus, supporting our hypothesis of a potential vertical transmission in the Pacific blue shrimp. Just as the eggs, the nauplii also displayed specific bacterial communities that were not found in the other samples (Fig. 5D). The most abundant genera were Profundimonas and

Marinobacterium which are both aerobic Gammaproteobacteria isolated from seawater samples ( González et al., 1997; Cao et al., 2014). Marinobacterium have also been highlighted in pipefish as a potential beneficial bacterium to larvae (Beemelmanns et al., 2019) and some strains are also known to hydrolyse chitine suggesting that they could play an important role in growth at nauplius stage. These ASVs were specifically identified in the nauplius samples and could have been vertically transmitted as well as for the eggs. Once again, as we studied active microbial communities, we can hypothesize that some bacterial communities are acquired from breeders and are activated at different developmental stages.

The nauplius samples could also be under the influence of bacterial communities associated with the eggs as specific ASVs seemed to be transmitted between the 2 sample types (Fig. 5C). These communities were mainly composed of Vibrio and Oleiphilus which have been identified in several marine environments and animals (Golyshin et al., 2002; Farmer et al., 2015). Aureispira bacteria were also abundant. They have been isolated from marine sponges and algae and are thus frequently found in marine organisms (Hosoya et al., 2006). Marinobacter and

Thalassolituus have been isolated in farmed shrimp experiments (Dineshkumar et al., 2014). Thalassolituus has also been identified at the nauplius stage of $L$. vannamei and has been suggested as a beneficial bacterium for larval development (Wang et al., 2020). Vibrio and Thalassolituus have also been identified in healthy adult shrimps (Rungrassamee et al., 2016; Wang et al., 2020) supporting our previous theory that some bacterial communities may be acquired from the breeders and kept throughout the whole lifecycle. Even though Vibrio sp. can be associated with diseases, they have been identified in adults and nauplii of L. vannamei shrimps regardless of their health status (Vandenberghe et al., 1999; Cornejo-Granados et al., 2017). Some species are even known to be selected in the environment by their host as symbionts (Nyholm \& McFall-Ngai, 2004).

\section{Possible dynamic interactions among compartments}

Interestingly, 5 genera (Vibrio, Marinobacter, Thalassotalea, Alteromonas and Aestuaribacter) were found in the ASVs shared between the eggs and the nauplii (Fig. 5C) but also in the ASVs shared between the water reservoirs and the animals (Fig. 4). Marinobacter and Aestuariibacter have been identified in the rearing environment of adult $L$. vannamei and brackishwater shrimps (Chen et al., 2019; Dineshkumar et al., 2014). Vibrio, Alteromonas and Thalassotalea have all been spotted in L. vannamei at different developmental stages as well as in the surrounding water (H. Wang et al., 2020; Zhang et al., 2014; Zheng et al., 2017). In our study, these genera were highlighted from different ASVs in different compartments, suggesting that some taxa may be acquired from the aquatic environment by the eggs and the nauplii but also by the breeders which 
412 then potentially transmit them to their offspring, supporting the hypothesis of a possible vertical

413 transmission of bacterial communities in L. stylirostris shrimp larvae (Fig 6). This also shows

414 that the microbiota associated to aquatic organisms and to their eggs are shaped by complex

415 interactions between environmental and transmitted microorganisms (Sylvain \& Derome, 2017).

416

\section{Conclusions}

418 To our knowledge, this study is the first to focus on the active microbiota of the eggs and the 419 nauplii of a farmed shrimp species while considering the impact of the rearing water. Taken 420 together, our results provide evidence of a core microbiota (Aestuariibacter, Alteromonas, 421 Vibrio, SAR11, HIMB11, AEGEAN 169 marine group, Candidatus Endobugula) among all samples suggesting a microbial transmission from the surrounding environment to the animals. As several ASVs were co-owned between the eggs and the nauplli, we also highlight a possible vertical transmission between the 2 compartments and potentially from the breeders as specific ASVs were not found in the rearing water (affiliated to Pseudomonas, Corynebacterium, Acinetobacter, Labrenzia, Rothia, Thalassolituus, Marinobacter, Aureispira, Oleiphilus, Profundimonas, Marinobacterium) (Fig. 6). This last point has not yet been confirmed as several male breeders are used to inseminate several females which produce eggs that are pooled before larval rearing thus, making it quite difficult to determine the genealogy of the shrimps and their offspring.

\section{Acknowledgements}

433

434

435

436

437

\section{8}

439

440

441

442

443

444

445

446

447

448

449

450

451

452

We are grateful to the SASV teams for their help throughout all the experiments: zootechny and laboratory support. We especially thank Jean-Sébastien Lam and Julien Le Rohellec for their precious help in the hatchery; Florence Antypas and Etienne Lopez for their contribution; as well as Valentine Ballan and Gwenola Plougoulen for their valuable biomolecular work.

\section{References}

Allali I., Arnold J. W., Roach J., Cadenas M. B., Butz N., Hassan H. M., Koci M., Ballou A., Mendoza M., Ali R., Azcarate-Peril M. A. (2017). A comparison of sequencing platforms and bioinformatics pipelines for compositional analysis of the gut microbiome. $B M C$ Microbiology, 17(1), 1-16. Doi: 10.1186/s12866-017-1101-8

Apprill A. (2017). Marine animal microbiomes: Toward understanding host-microbiome interactions in a changing ocean. Frontiers in Marine Science, 4(JUL), 1-9. Doi: 10.3389/fmars.2017.00222

Bardou P., Mariette J., Escudié F., Djemiel C., Klopp C. (2014). SOFTWARE Open Access jvenn: an interactive Venn diagram viewer. BMC Bioinformatics, 15(293), 1-7. Retrieved from http://www.biomedcentral.com/1471-2105/15/293

Beemelmanns A., Poirier M., Bayer T., Kuenzel S., Roth O. (2019). Microbial embryonal colonization during pipefish male pregnancy. Scientific Reports, 9(1), 1-14. Doi: 10.1038/s41598-018-37026-3

Beliaeff B., Chim L., Della Patrona L., Goyard E., Herlin J., Labreache Y., Walling E., Ansquer D., Brun P., Castex M., Coatanea D., Courties C., De Lorgeril J., Dufour R., Frappier J., Goarant C., Huber M., Lemaire P., Lemonnier H., Le Roux F., Loubersac L., Lucas R., Patrois J., Peignon J.-M., Pham D., Ramage Y., Soulard B., Vic M., Vourey E., \& Wabete N. (2009). DEDUCTION: A Research Project for Shrimp Farming Sustainability in New 
457

458

459

460

461

462

463

464

465

466

467

468

469

470

471

472

473

474

475

476

477

478

479

480

481

482

483

484

485

486

487

488

489

490

491

492

493

494

495

496

497

498

499

500

501

502

Caledonia.

Ben-Dov E., Yosef D. Z.B., Pavlov V., Kushamro A. (2009). Corynebacterium maris sp. nov., a marine bacterium isolated from the mucus of the coral Fungia granulosa. International Journal of Systematic and Evolutionary Microbiology, 59(10), 2458-2463. Doi: 10.1099/ijs.0.007468-0

Blazewicz S. J., Barnard R. L., Daly R. A., Firestone M. K. (2013). Evaluating rRNA as an indicator of microbial activity in environmental communities: Limitations and uses. ISME Journal, 7(11), 2061-2068. Doi: 10.1038/ismej.2013.102

Britschgi T. B., Giovannoni S. J. (1991). Phylogenetic analysis of a natural marine bacterioplankton population by rRNA gene cloning and sequencing. Applied and Environmental Microbiology, 57(6), 1707-1713. Doi: 10.1128/aem.57.6.1707-1713.1991

Bushel P. R., Ferguson S. S., Ramaiahgari S. C., Paules,R. S., Auerbach S. S. (2020). Comparison of Normalization Methods for Analysis of TempO-Seq Targeted RNA Sequencing Data. Frontiers in Genetics, 11(June), 1-11. Doi: 10.3389/fgene.2020.00594

Callahan B. J., McMurdie P. J., Holmes S. P. (2017). Exact sequence variants should replace operational taxonomic units in marker-gene data analysis. The ISME Journal, 11(12), 26392643. Doi: 10.1038/ismej.2017.119

Callahan B. J., McMurdie P. J., Rosen M. J., Han A. W., Johnson A. J. A., Holmes S. P. (2016). DADA2: High-resolution sample inference from Illumina amplicon data. Nature Methods, 13(7), 581-583. Doi: 10.1038/nmeth.3869

Cao Y., Chastain R. A., Eloe E. A., Nogi Y., Kato C., Bartletta D. H. (2014). Novel psychropiezophilic oceanospirillales species profundimonas piezophila gen. nov., sp. nov., isolated from the deep-sea environment of the puerto rico trench. Applied and Environmental Microbiology, 80(1), 54-60. Doi: 10.1128/AEM.02288-13

Caporaso J. G., Lauber C. L., Walters W. A., Berg-Lyons D., Lozupone C. A., Turnbaugh P. J., Fierer N., Knight R. (2011). Global patterns of 16S rRNA diversity at a depth of millions of sequences per sample. Proceedings of the National Academy of Sciences of the United States of America, 108(SUPPL. 1), 4516-4522. Doi: 10.1073/pnas.1000080107

Chan K. Y., Baumann L., Garza M. M., Baumann P. (1978). Alteromonas: Alteromonas espejiana. 28(2), 217-222.

Chen Z., Chang Z., Zhang L., Jiang Y., Ge H., Song X., Chen S., Zhao F., Li J. (2019). Effects of water recirculation rate on the microbial community and water quality in relation to the growth and survival of white shrimp (Litopenaeus vannamei). BMC Microbiology, 19(1), 115. Doi: 10.1186/s12866-019-1564-x

Cho I., Blaser M. J. (2012). APPLICATIONS OF NEXT-GENERATION SEQUENCING The human microbiome: at the interface of health and disease. Nature Reviews Genetics, 13(4), 260-270. Doi: 10.1038/nrg3182.The

Cho J. C., Stapels M. D., Morris R. M., Vergin K. L., Schwalbach M. S., Givan S. A., Barofsky D. F., Giovannoni S. J. (2007). Polyphyletic photosynthetic reaction centre genes in oligotrophic marine Gammaproteobacteria. Environmental Microbiology, 9(6), 1456-1463. Doi: 10.1111/j.1462-2920.2007.01264.x

Cornejo-Granados F., Lopez-Zavala A. A., Gallardo-Becerra L., Mendoza-Vargas A., Sánchez F., Vichido R., Brieba L. G., Viana M. T., Sotelo-Mundo R. R., Ochoa-Leyva A. (2017). Microbiome of Pacific Whiteleg shrimp reveals differential bacterial community composition between Wild, Aquacultured and AHPND/EMS outbreak conditions. Scientific Reports, 7(1), 11783. Doi: 10.1038/s41598-017-11805-w 
503 Cram J. A., Xia L. C., Needham D. M., Sachdeva R., Sun F., Fuhrman J. A. (2015). Cross-depth analysis of marine bacterial networks suggests downward propagation of temporal changes. ISME Journal, 9(12), 2573-2586. Doi: 10.1038/ismej.2015.76

505

506

507

Dineshkumar N., Saravanakumar C., Vasanth M., Muralidhar M., Alavandi S. V. (2014). Genetic and physiological characterization of denitrifying bacteria from brackishwater

508 shrimp culture ponds of India. International Biodeterioration and Biodegradation, 92, 4956. Doi: 10.1016/j.ibiod.2014.04.017

510

511

512

513

514

515

516

517

Durán-Avelar M. de J., Vázquez-Reyes A., González-Mercado A. L., Zambrano-Zaragoza J. F., Ayón-Pérez M. F., Agraz-Cibrián J. M., Gutiérrez-Franco J., Vibanco-Pérez N. (2018). pirA- and pirB-like gene identification in Micrococcus luteus strains in Mexico. Journal of Fish Diseases, 41(11), 1667-1673. Doi: 10.1111/jfd.12874

Durham B. P., Grote J., Whittaker K. A., Bender S. J., Luo H., Grim S. L., Brown J. M., Casey J. R., Dron A., Florez-Leiva L., Krupke A., Luria C. M., Mine A. H., Nigro O. D., Pather S., Talarmin A., Wear E. K., Weber T. S., Wilson J. M., Rappé M. S. (2014). Draft genome sequence of marine alphaproteobacterial strain HIMB11, the first cultivated representative of a unique lineage within the Roseobacter clade possessing an unusually small genome. Standards in Genomic Sciences, 9(3), 632-645. Doi: 10.4056/sigs.4998989

Egan S., Gardiner M. (2016). Microbial dysbiosis: Rethinking disease in marine ecosystems. Frontiers in Microbiology, 7(JUN), 1-8. Doi: 10.3389/fmicb.2016.00991

Falkowski P. G., Fenchel T., Delong E. F. (2008). The microbial engines that drive earth's biogeochemical cycles. Science, 320(5879), 1034-1039. Doi: 10.1126/science.1153213

Farmer J. J., Michael Janda J., Brenner F. W., Cameron D. N., Birkhead K. M. (2015). Vibrio. In Bergey's Manual of Systematics of Archaea and Bacteria. Doi:

10.1002/9781118960608.gbm01078

Fournier P. E., Richet H. (2006). The epidemiology and control of Acinetobacter baumannii in health care facilities. Clinical Infectious Diseases, 42(5), 692-699. Doi: 10.1086/500202

Freitas S., Hatosy S., Fuhrman J. A., Huse S. M., Mark Welch D. B., Sogin M. L., Martiny A. C. (2012). Global distribution and diversity of marine Verrucomicrobia. ISME Journal, 6(8), 1499-1505. Doi: 10.1038/ismej.2012.3

Fuerst J. A. (1995). The planctomycetes: Emerging models for microbial ecology, evolution and cell biology. Microbiology, 141(7), 1493-1506. Doi: 10.1099/13500872-141-7-1493

Galili T. (2015). dendextend: An R package for visualizing, adjusting and comparing trees of hierarchical clustering. Bioinformatics, 31(22), 3718-3720. Doi : 10.1093/BIOINFORMATICS/BTV428

Ghai R., Mizuno C. M., Picazo A., Camacho A., Rodriguez-Valera F. (2013). Metagenomics uncovers a new group of low GC and ultra-small marine Actinobacteria. Scientific Reports, 3, 1-8. Doi: 10.1038/srep02471

Giovannoni S. J., Stingl U. (2005). Molecular diversity and ecology of microbial plankton. Nature, 437(7057), 343-348. Doi: 10.1038/nature04158

Glassman S. I., Martiny J. B. H. (2018). Broadscale Ecological Patterns Are Robust to Use of Exact. MSphere, 3(4), e00148-18.

Goarant C., Ansquer D., Herlin J., Domalain D., Imbert F., De Decker S. (2006). "Summer Syndrome" in Litopenaeus stylirostris in New Caledonia: Pathology and epidemiology of the etiological agent, Vibrio nigripulchritudo. Aquaculture, 253(1-4), 105-113. Doi: 10.1016/j.aquaculture.2005.07.031

Goarant C., Merien F., Berthe F., Mermoud I., Perolat P. (1999). Arbitrarily Primed PCR To 
549

550

551

552

553

554

555

556

557

558

559

560

561

562

563

564

565

566

567

568

569

570

571

572

573

574

575

576

577

578

579

580

581

582

583

584

585

586

587

588

589

590

591

592

593

594

Type Vibriospp. Pathogenic for Shrimp. Applied and Environmental Microbiology, 65(3), 1145-1151. Doi: 10.1128/AEM.65.3.1145-1151.1999

Golyshin P. N., Chernikova Ta. N., Abraham W. R., Lünsdorf H., Timmis K. N., Yakimov M. M. (2002). Oleiphilaceae fam. nov., to include Oleiphilus messinensis gen. nov., sp. nov., a novel marine bacterium that obligately utilizes hydrocarbons. International Journal of Systematic and Evolutionary Microbiology, 52(3), 901-911. Doi: 10.1099/ijs.0.01890-0 Gómez-Pereira P. R., Fuchs B. M., Alonso C., Oliver M. J., Van Beusekom J. E., Amann R. (2010). Distinct flavobacterial communities in contrasting water masses of the North Atlantic Ocean. ISME Journal, 4(4), 472-487. Doi: 10.1038/ismej.2009.142

González J. M., Mayer F., Moran M. A., Hodson R. E., Whitman W. B. (1997). Microbulbifer hydrolyticus gen. nov., sp. nov., and Marinobacterium georgiense gen. nov., sp. nov., two marine bacteria from a lignin-rich pulp mill waste enrichment community. International Journal of Systematic Bacteriology, 47(2), 369-376. Doi: 10.1099/00207713-47-2-369

Hansen G. H., Olafsen J. A. (1999). Bacterial interactions in early life stages of marine cold water fish. Microbial Ecology, 38(1), 1-26. Doi: 10.1007/s002489900158

Harrison K. E. (1997). Broodstock nutrition and maturation diets. In L. R. D’Abramo, D. E. Conklin, D. M. Akiyama (Eds.), Advances in world aquaculture (volume 6), crustacean nutrition (pp. 390-401). World Aquaculture Society.

Helms J. R., Stubbins A., Ritchie J. D., Minor E. C., Kieber D. J., Mopper K. (2009). Erratum: Absorption spectral slopes and slope ratios as indicators of molecular weight, source, and photobleaching of chromophoric dissolved organic matter. Limnology and Oceanography, 54(3), 1023-1023. Doi: 10.4319/10.2009.54.3.1023

Hosoya S., Arunpairojana V., Suwannachart C., Kanjana-Opas A., Yokota A. (2006). Aureispira marina gen. nov., sp. nov., a gliding, arachidonic acid-containing bacterium isolated from the southern coastline of Thailand. International Journal of Systematic and Evolutionary Microbiology, 56(12), 2931-2935. Doi: 10.1099/ijs.0.64504-0

Hunt D. E., Gevers D., Vahora N. M., Polz M. F. (2008). Conservation of the chitin utilization pathway in the Vibrionaceae. Applied and Environmental Microbiology, 74(1), 44-51. Doi: 10.1128/AEM.01412-07

Huttenhower C., Gevers D., Knight R., Abubucker S., Badger J. H., Chinwalla A. T., Creasy H. H., Earl A. M., Fitzgerald M. G., Fulton R. S., Giglio M. G., Hallsworth-Pepin K., Lobos E. A., Madupu R., Magrini V., Martin J. C., Mitreva M., Muzny D. M., Sodergren E. J., White O. (2012). Structure, function and diversity of the healthy human microbiome. Nature, 486(7402), 207-214. Doi: 10.1038/nature11234

Jaroenram W., Owens L., Hayakijkosol O., \& Elliman J. (2021). Natural, in ovo, vertical transmission of the RNA viruses, Chequa iflavirus and Athtab bunyavirus, but not Cherax reovirus in redclaw crayfish (Cherax quadricarinatus). Aquaculture, 534(November 2020), 736285. https://doi.org/10.1016/j.aquaculture.2020.736285

Judd K. E., Crump B. C., Kling G. W. (2006). Variation in dissolved organic matter controls bacterial production and community composition. Ecology, 87(8), 2068-2079. Doi: 10.1890/0012-9658(2006)87[2068:VIDOMC]2.0.CO;2

McMurdie P. J., Holmes S. (2014). Waste Not, Want Not: Why Rarefying Microbiome Data Is Inadmissible. PLoS Computational Biology, 10(4). Doi: 10.1371/journal.pcbi.1003531

Methou P., Hernández-Ávila I., Aube J., Cueff-Gauchard V., Gayet N., Amand L., Shillito B., Pradillon F., Cambon-Bonavita M.-A. (2019). Is It First the Egg or the Shrimp? - Diversity and Variation in Microbial Communities Colonizing Broods of the Vent Shrimp Rimicaris 
595

596

597

598

599

600

601

602

603

604

605

606

607

608

609

610

611

612

613

614

615

616

617

618

619

620

621

622

623

624

625

626

627

628

629

630

631

632

633

634

635

636

637

638

639

640

exoculata During Embryonic Development. Frontiers in Microbiology, 10(MAR), 1-19.

Doi: 10.3389/fmicb.2019.00808

Moloney R. D., Desbonnet L., Clarke G., Dinan T. G., Cryan J. F. (2014). The microbiome: Stress, health and disease. Mammalian Genome, 25(1-2), 49-74. Doi: 10.1007/s00335-0139488-5

Mora C., Tittensor D. P., Adl S., Simpson A. G. B., Worm B. (2011). How many species are there on earth and in the ocean? PLoS Biology, 9(8), 1-8. Doi: 10.1371/journal.pbio. 1001127

Morris R. M., Rappé M. S., Connon S. A., Vergin K. L., Siebold W. A., Carlson C. A., Giovannoni S. J. (2002). SAR11 clade dominates ocean surface bacterioplankton communities. Nature, 420(6917), 806-810. Doi: 10.1038/nature01240

Nyholm S. V. (2020). In the beginning: Egg-microbe interactions and consequences for animal hosts: Egg microbiomes in animals. Philosophical Transactions of the Royal Society B: Biological Sciences, 375(1808). Doi: 10.1098/rstb.2019.0593rstb20190593

Nyholm S. V., McFall-Ngai M. J. (2004). The winnowing: Establishing the squid - Vibrios symbiosis. Nature Reviews Microbiology, 2(8), 632-642. Doi: 10.1038/nrmicro957

Oksanen J., Blanchet F. G., Friendly M., Kindt R., Legendre P., McGlinn D., Minchin P. R., O’Hara R. B., Simpson G. L., Solymos P., Stevens M. H. H., Szoecs E., Wagner H. (2020). CRAN - Package vegan. Retrieved from https://cran.rproject.org/web/packages/vegan/index.html

Orsi W. D., Smith J. M., Liu S., Liu Z., Sakamoto C. M., Wilken S., Poirier C., Richards T. A., Keeling P. J., Worden A. Z., Santoro A. E. (2016). Diverse, uncultivated bacteria and archaea underlying the cycling of dissolved protein in the ocean. ISME Journal, 10(9), 2158-2173. Doi: 10.1038/ismej.2016.20

Osterholz H., Kirchman D. L., Niggemann J., Dittmar T. (2018). Diversity of bacterial communities and dissolved organic matter in a temperate estuary. FEMS Microbiology Ecology, 94(8), 1-11. Doi: 10.1093/femsec/fiy119

Palleroni N. J. (2015). Pseudomonas . In Bergey's Manual of Systematics of Archaea and Bacteria. Doi: 10.1002/9781118960608.gbm01210

Pangastuti A., Suwanto A., Lestari Y., Tennawijaya Suhartono M. (2009). Bacterial communities associated with white shrimp (Litopenaeus vannamei) larvae at early developmental stages. Biodiversitas Journal of Biological Diversity, 11(2), 65-68. Doi: 10.13057/biodiv/d110203

Partensky F., Vaulot D. (1999). Cyanobacterial photosynthetic apparatus: an overview. Marine Cyanobacteria, 19(19), 457-475. Retrieved from http://cat.inist.fr/?aModele $=$ afficheN\&cpsidt=1218663

Pham D., Charmantier G., Wabete N., Boulo V., Broutoi F., Mailliez J.-R., Peignon J.-M., Charmantier-Daures M. (2012). Salinity tolerance, ontogeny of osmoregulation and zootechnical improvement in the larval rearing of the Caledonian Blue Shrimp, Litopenaeus stylirostris (Decapoda, Penaeidae). Aquaculture, 362-363, 10-17. Doi:

10.1016/j.aquaculture.2012.07.026

Porter T. M., Hajibabaei M. (2020). Putting COI Metabarcoding in Context : The Utility of Exact Sequence Variants (ESVS ) in Biodiversity Analysis. 8(August), 1-15. Doi: 10.3389/fevo.2020.00248

Quast C., Pruesse E., Yilmaz P., Gerken J., Schweer T., Yarza P., Peplies J., Doi Glöckner F. O. (2013). The SILVA ribosomal RNA gene database project: Improved data processing and 
641

642

643

644

645

646

647

648

649

650

651

652

653

654

655

656

657

658

659

660

661

662

663

664

665

666

667

668

669

670

671

672

673

674

675

676

677

678

679

680

681

682

683

684

685

686

web-based tools. Nucleic Acids Research, 41(D1), 590-596. Doi: 10.1093/nar/gks1219

Raj Sharma A., Zhou T., Harunari E., Oku N., Trianto A., Doi Igarashi Y. (2019). Labrenzbactin from a coral-associated bacterium Labrenzia sp. Journal of Antibiotics, 72(8), 634-639.

Doi: 10.1038/s41429-019-0192-x

Robinson M. D., McCarthy D. J., Smyth G. K. (2009). edgeR: A Bioconductor package for differential expression analysis of digital gene expression data. Bioinformatics, 26(1), 139140. Doi: 10.1093/bioinformatics/btp616

RStudio Team. (2020). RStudio: Integrated Development for R. RStudio, PBC, Boston, MA. Retrieved from http://www.rstudio.com/

Rungrassamee W., Klanchui A., Chaiyapechara S., Maibunkaew S., Tangphatsornruang S., Jiravanichpaisal P., Doi Karoonuthaisiri N. (2013). Bacterial Population in Intestines of the Black Tiger Shrimp (Penaeus monodon) under Different Growth Stages. PLoS ONE, 8(4). Doi: 10.1371/journal.pone.0060802

Rungrassamee W., Klanchui A., Maibunkaew S., Doi Karoonuthaisiri N. (2016). Bacterial dynamics in intestines of the black tiger shrimp and the Pacific white shrimp during Vibrio harveyi exposure. Journal of Invertebrate Pathology, 133, 12-19. Doi: 10.1016/j.jip.2015.11.004

Sadeghi-Nassaj S. M., Catalá T. S., Álvarez P. A., Doi Reche I. (2018). Sea cucumbers reduce chromophoric dissolved organic matter in aquaculture tanks. PeerJ, 2018(2), 1-20. Doi: 10.7717/peerj.4344

Sehnal L., Brammer-Robbins E., Wormington A. M., Blaha L., Bisesi J., Larkin I., Martyniuk C. J., Simonin M., Doi Adamovsky O. (2021). Microbiome Composition and Function in Aquatic Vertebrates: Small Organisms Making Big Impacts on Aquatic Animal Health. Frontiers in Microbiology, 12(March). Doi: 10.3389/fmicb.2021.567408

Shade A., Handelsman J. (2012). Beyond the Venn diagram: The hunt for a core microbiome. Environmental Microbiology, 14(1), 4-12. Doi: 10.1111/j.1462-2920.2011.02585.x

Suzuki M. T., Béjà O., Taylor L. T., Doi DeLong E. F. (2001). Phylogenetic analysis of ribosomal RNA operons from uncultivated coastal marine bacterioplankton. Environmental Microbiology, 3(5), 323-331. Doi: 10.1046/j.1462-2920.2001.00198.x

Sylvain F. É., Derome N. (2017). Vertically and horizontally transmitted microbial symbionts shape the gut microbiota ontogenesis of a skin-mucus feeding discus fish progeny. Scientific Reports, 7(1), 1-14. Doi: 10.1038/s41598-017-05662-w

Tsuzukibashi O., Uchibori S., Kobayashi T., Umezawa K., Mashimo C., Nambu T., Saito M., Hashizume-Takizawa T., Doi Ochiai T. (2017). Isolation and identification methods of Rothia species in oral cavities. Journal of Microbiological Methods, 134, 21-26. Doi: 10.1016/j.mimet.2017.01.005

Vadstein O., Attramadal K. J. K., Bakke I., Doi Olsen Y. (2018). K-selection as microbial community management strategy: A method for improved viability of larvae in aquaculture. Frontiers in Microbiology, 9(NOV), 1-17. Doi: 10.3389/fmicb.2018.02730

Vandenberghe J., Verdonck L., Robles-Arozarena R., Rivera G., Bolland A., Balladares M., Gomez-Gil B., Calderon J., Sorgeloos P., Doi Swings J. (1999). Vibrios Associated with Litopenaeus vannamei Larvae, Postlarvae, Broodstock, and Hatchery Probionts. Applied and Environmental Microbiology, 65(6), 2592-2597. Doi: 10.1128/AEM.65.6.25922597.1999

Wang H., Huang J., Wang P., Doi Li T. (2020). Insights into the microbiota of larval and postlarval Pacific white shrimp (Penaeus vannamei) along early developmental stages: a 
687

case in pond level. Molecular Genetics and Genomics, 295(6), 1517-1528. Doi: 10.1007/s00438-020-01717-2

Wang Y., Wang K., Huang L., Dong P., Wang S., Chen H., Lu Z., Hou D., Doi Zhang D. (2020). Fine-scale succession patterns and assembly mechanisms of bacterial community of Litopenaeus vannamei larvae across the developmental cycle. Microbiome, 8(1), 106. Doi: 10.1186/s40168-020-00879-w

Weiss S., Xu Z. Z., Peddada S., Amir A., Bittinger K., Gonzalez A., Lozupone C., Zaneveld J. R., Vázquez-Baeza Y., Birmingham A., Hyde E. R., Doi Knight R. (2017). Normalization and microbial differential abundance strategies depend upon data characteristics. Microbiome, 5(1), 27. Doi: 10.1186/s40168-017-0237-y

Whitman W. B., Coleman D. C., Wiebe W. J. (1998). Prokaryotes: The unseen majority. Proceedings of the National Academy of Sciences, 95(12), 6578-6583. Doi: 10.1073/pnas.95.12.6578

Wickham H. (2016). ggplot2: Elegant Graphics for Data Analysis. Springer-Verlag New York. ISBN 978-3-319-24277-4

Wickham H., François R., Henry L., Doi Müller K. (2021). CRAN - Package dplyr. Retrieved from https://cran.r-project.org/web/packages/dplyr/index.html

Yi H., Bae K. S., Chun J. (2004). Aestuariibacter salexigens gen. nov., sp. nov. and Aestuariibacter halophilus sp. nov., isolated from tidal flat sediment, and emended description of Alteromonas macleodii. International Journal of Systematic and Evolutionary Microbiology, 54(2), 571-576. Doi: 10.1099/ijs.0.02798-0

Zeng S., Huang Z., Hou D., Liu J., Weng S., Doi He J. (2017). Composition, diversity and function of intestinal microbiota in pacific white shrimp (Litopenaeus vannamei) at different culture stages. PeerJ, 2017(11). Doi: 10.7717/peerj.3986

Zhang M., Sun Y., Chen K., Yu N., Zhou Z., Chen L., Du Z., Doi Li E. (2014). Characterization of the intestinal microbiota in Pacific white shrimp, Litopenaeus vannamei, fed diets with different lipid sources. Aquaculture, 434, 449-455. Doi: 10.1016/j.aquaculture.2014.09.008

Zheng Y., Yu M., Liu J., Qiao Y., Wang L., Li Z., Zhang X.-H., Doi Yu M. (2017). Bacterial Community Associated with Healthy and Diseased Pacific White Shrimp (Litopenaeus vannamei) Larvae and Rearing Water across Different Growth Stages. Frontiers in Microbiology, 8(JUL), 1-11. Doi: 10.3389/fmicb.2017.01362

Zinger L., Amaral-Zettler L. A., Fuhrman J. A., Horner-Devine M. C., Huse S. M., Welch D. B. M., Martiny J. B. H., Sogin M., Boetius A., Doi Ramette A. (2011). Global patterns of bacterial beta-diversity in seafloor and seawater ecosystems. PLoS ONE, 6(9), 1-11. Doi: 10.1371/journal.pone.0024570 


\section{Table $\mathbf{1}$ (on next page)}

CDOM concentrations and slope ratios in the reservoirs.

Values of CDOM concentration (a[325) and slope ratios (SR) from 275 to $295 \mathrm{~nm}$ and from 350 to $400 \mathrm{~nm}$ of the primary and the secondary reservoir (Resl and Resll) samples of the M1, M3 and M4 experiments. 


\begin{tabular}{|c|c|c|c|}
\cline { 3 - 4 } \multicolumn{2}{c|}{} & ResI & ResII \\
\hline \multirow{2}{*}{ M1 } & $\mathbf{a} \lambda \mathbf{3 2 5}\left(\mathbf{m}^{-\mathbf{1}}\right)$ & 0.99 & 1.01 \\
\cline { 2 - 4 } & $\mathbf{S R}$ & 7.06 & 4.79 \\
\hline \multirow{2}{*}{ M3 } & $\mathbf{a} \lambda \mathbf{3 2 5}\left(\mathbf{m}^{-1}\right)$ & 0.83 & 0.82 \\
\cline { 2 - 4 } & $\mathbf{S R}$ & 7.67 & 8.12 \\
\hline \multirow{2}{*}{ M4 } & $\mathbf{a} \lambda \mathbf{3 2 5}\left(\mathbf{m}^{-1}\right)$ & 1.06 & 0.98 \\
\cline { 2 - 4 } & $\mathbf{S R}$ & 5.98 & 6.27 \\
\hline
\end{tabular}




\section{Figure 1}

Bacterial compositions and clustering of all samples.

(A) Hierarchical clustering based on Bray-Curtis dissimilarity. In order to define clusters, a 1.5 threshold was set (represented by the red dotted line). All the water samples are clustered in Cluster 1, in light grey. All the egg and the nauplius (nii) samples are clustered in Cluster 2 , in dark grey. (B) Bacterial compositions of the primary reservoir (Resl), the secondary reservoir (Resll), the egg and the nauplius (nii) samples. The highlighted bacterial classes have a total relative abundance higher than $1 \%$.

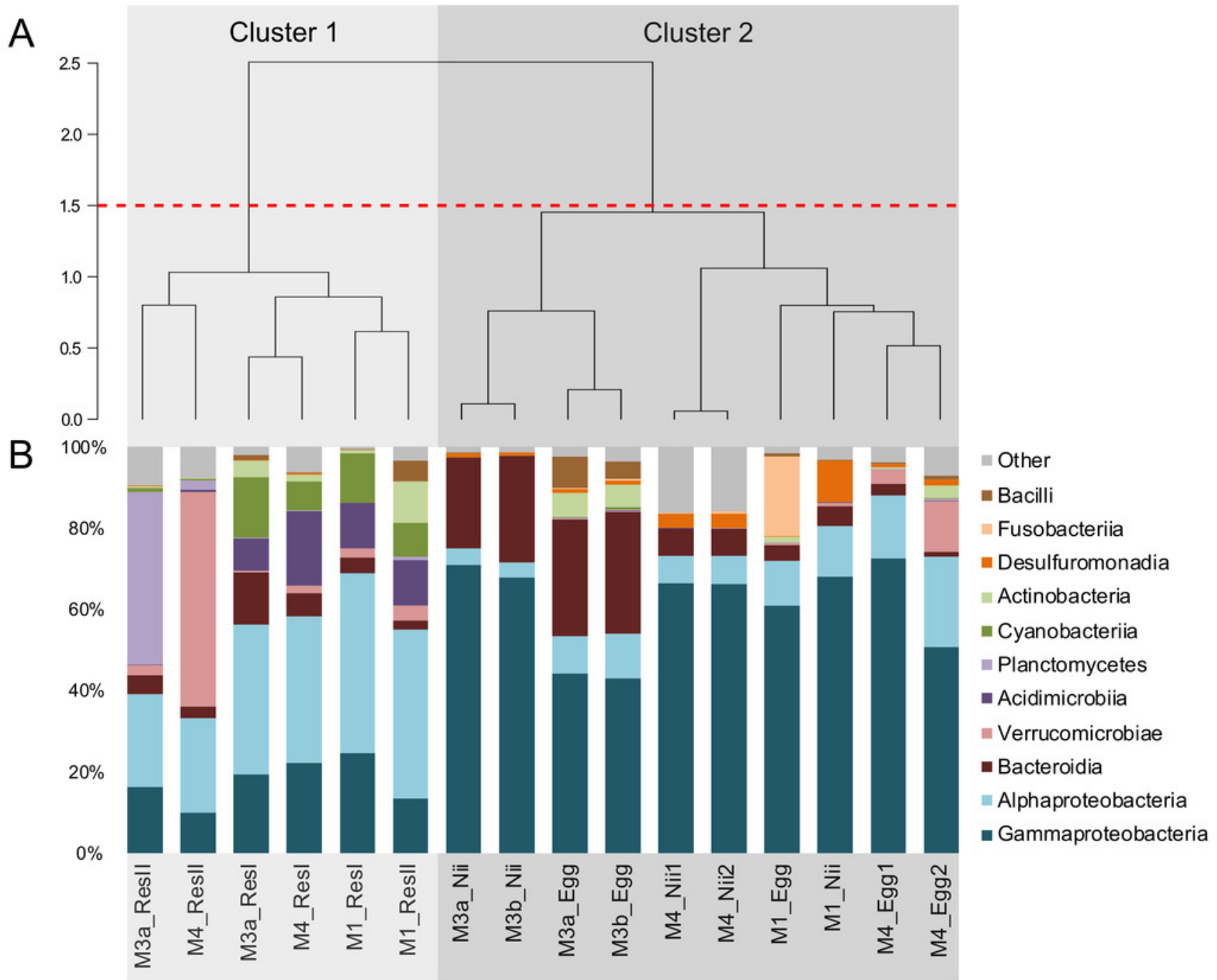




\section{Figure 2}

Venn diagram of shared ASVs among experiments and sample types.

The green ellipse represents the ASVs common to all the egg samples. The blue ellipse represents the ASVs common to all the nauplius (nii) samples. The red ellipse represents the ASVs common to all the primary reservoir (Resl) samples. The yellow ellipse represents the ASVs common to all the secondary reservoir (Resll) samples. Numbers noted in the overlapping areas correspond to shared ASVs among compartments. Numbers noted outside of the overlapping areas correspond to specific ASVs. A) Specific and shared ASVs among the water samples. B) Shared core microbiota among all sample types. C) Specific and shared ASVs among the egg and the nauplius samples. 


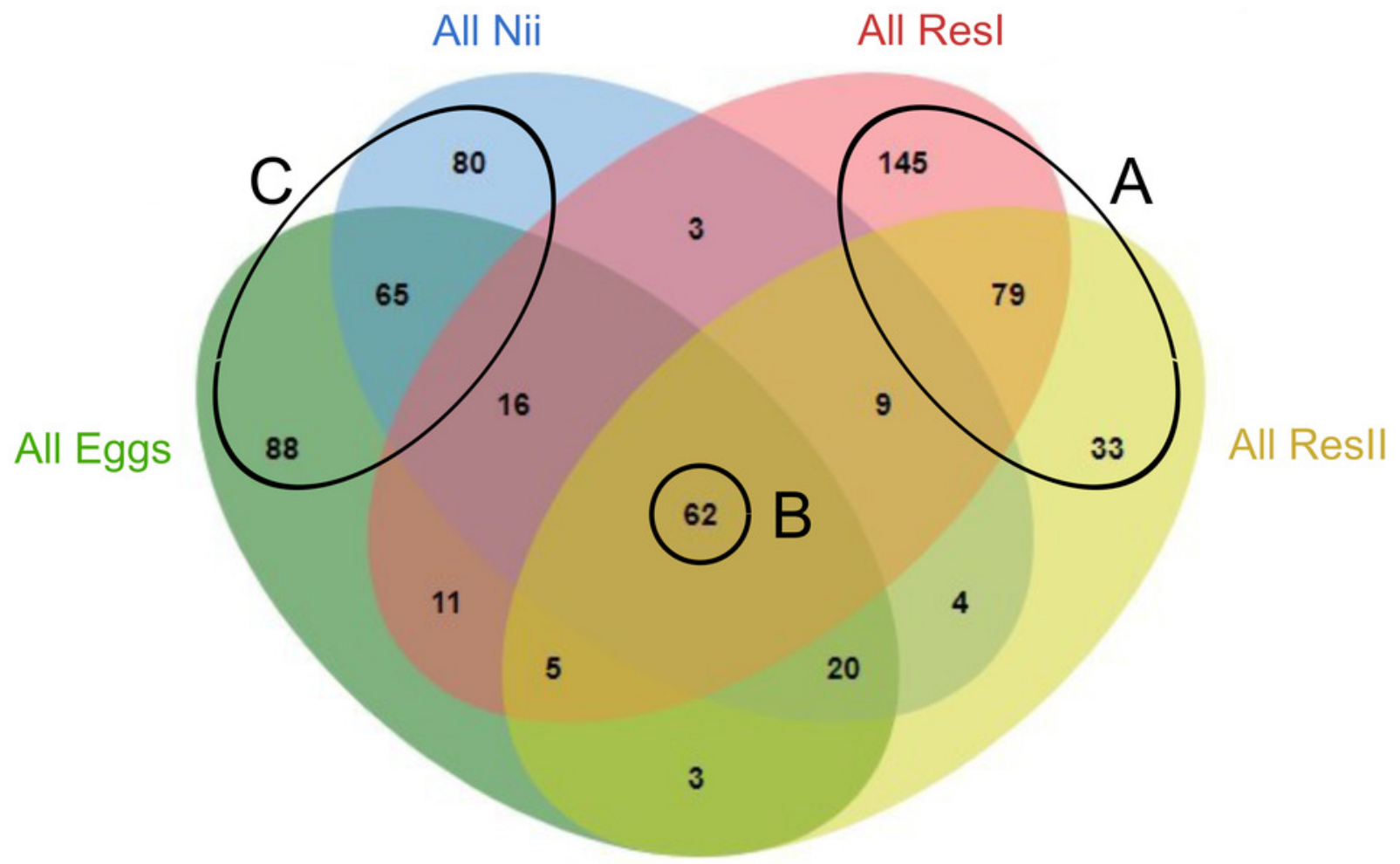




\section{Figure 3}

Bacterial communities associated with the primary and the secondary reservoirs.

Top bacterial lineages (up to genus when possible) with a relative abundance higher than $1 \%$ and specifically found in (A) the primary and the secondary reservoir water samples (Resl and Res(I). Histograms were built using the abundance of the selected subset of ASVs. Top bacterial lineages (B) uniquely found in the primary reservoir (ResI) samples (148 ASVs, in red in the Venn diagram), (C) shared between all the water samples (79 ASVs, in the intersection of the red and yellow ellipses) and (D) uniquely found in the secondary reservoir (ResIl) samples (33 ASVs, in yellow in the Venn diagram). The arrows represent the potential ASV transmission among compartments. 


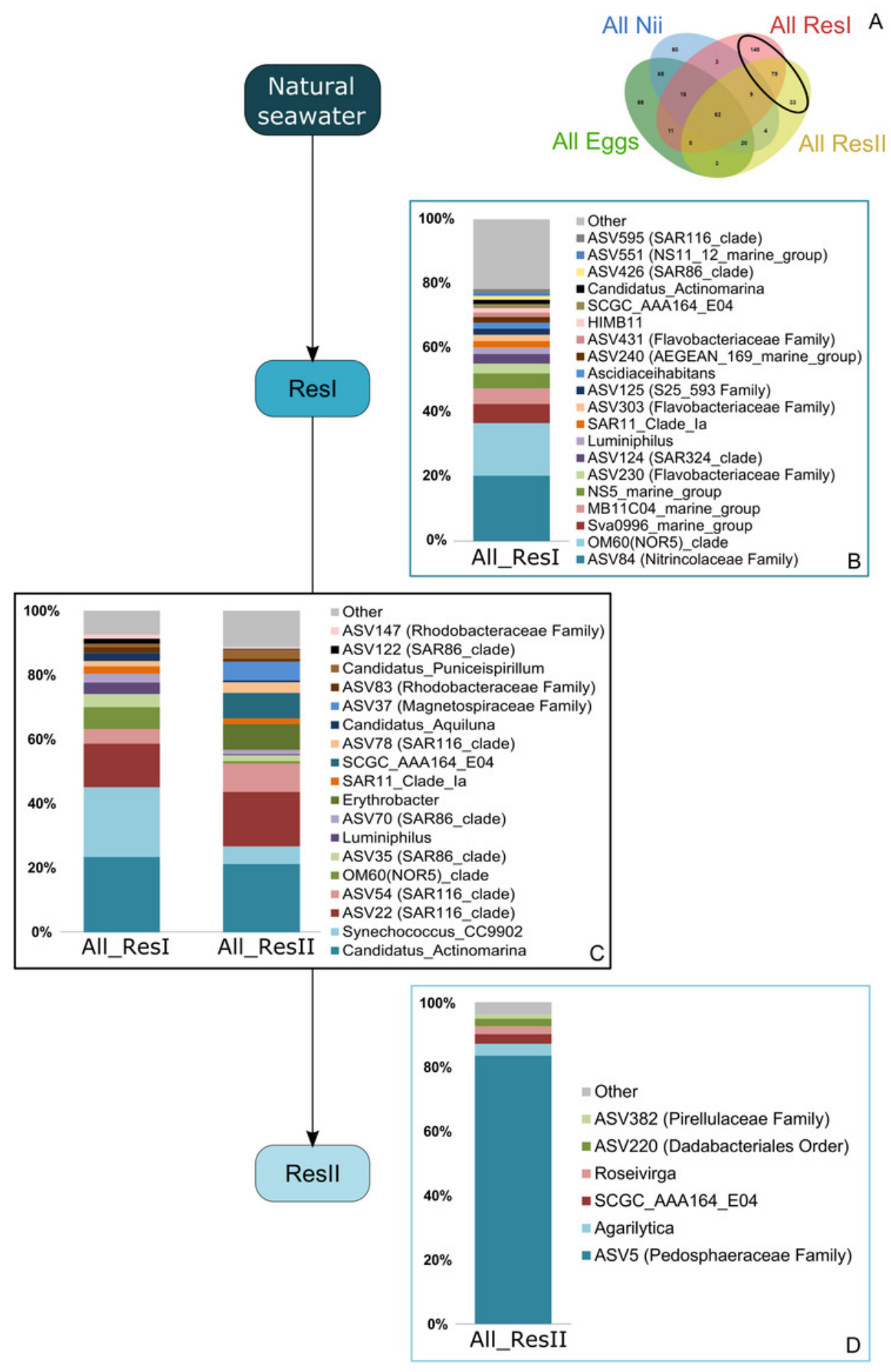




\section{Figure 4}

Bacterial communities associated with all samples.

Top bacterial lineages (up to genus when possible) composing the $(A)$ shared core microbiota among all samples (62 ASVs). Histograms were built using the abundance of the selected subset of ASVs. The highlighted bacterial lineages have a total relative abundance higher than $1 \%$ but are distributed unevenly among (B) the primary reservoir (Resl) samples, $(C)$ the secondary reservoir (Resll) samples, (D) the egg samples and (E) the nauplius (nii) samples. The arrows represent the potential ASV transmission among compartments. 


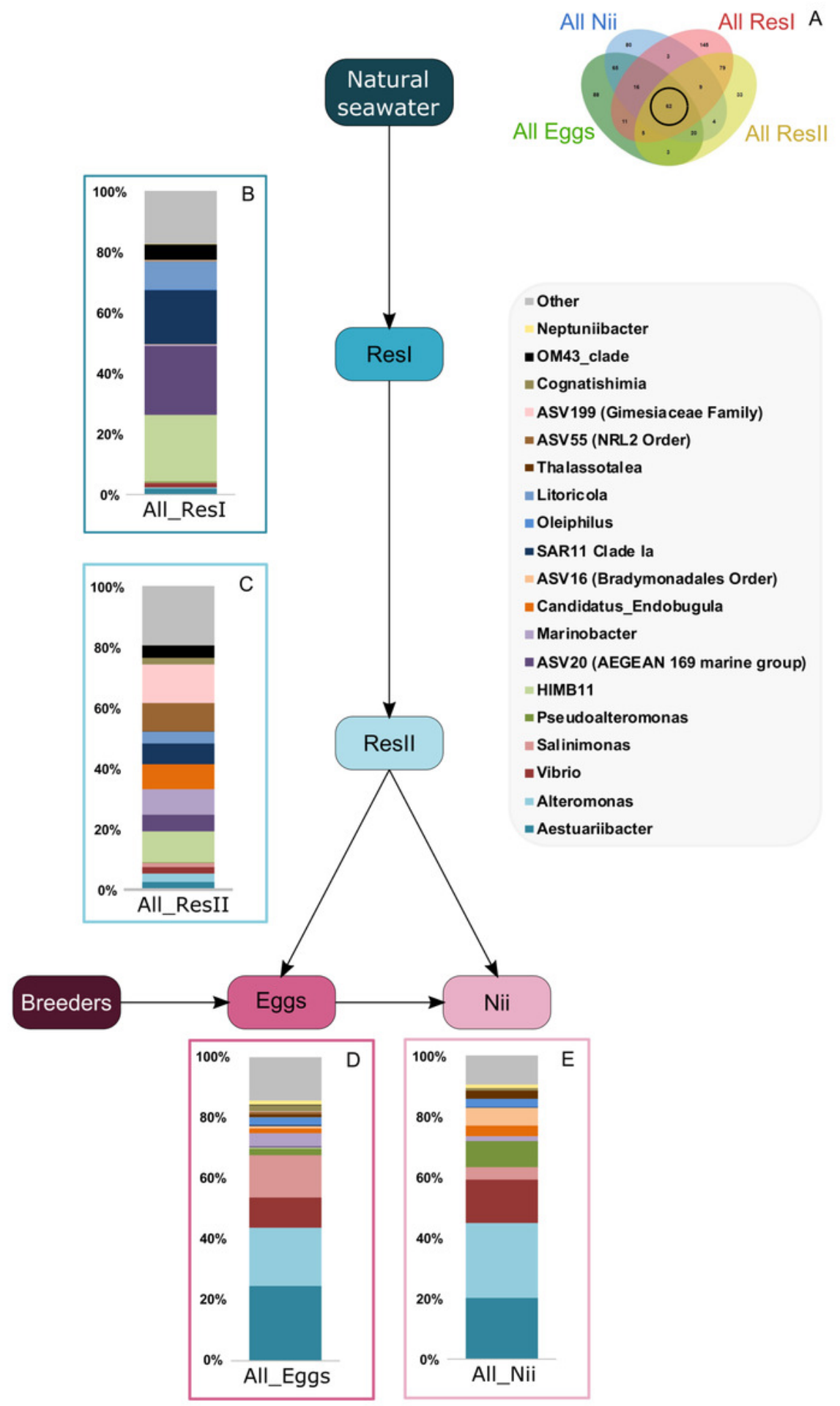




\section{Figure 5}

Bacterial communities associated with the eggs and the nauplii.

Top bacterial lineages (up to genus when possible) with a realtive abundance higher than $1 \%$ and specifically found in (A) the egg and the nauplius (nii). Histograms were built using the abundance of the selected subset of ASVs. Top bacterial lineages (B) uniquely found in the egg samples (88 ASVs, in green in the Venn diagram), (C) shared between all the egg and the nauplius (nii) samples (65 ASVs, in the intersection of the green and blue ellipses) and (D) uniquely found in the nauplius (nii) samples (88 ASVs, in blue in the Venn diagram). The arrows represent the potential ASV transmission among compartments. 


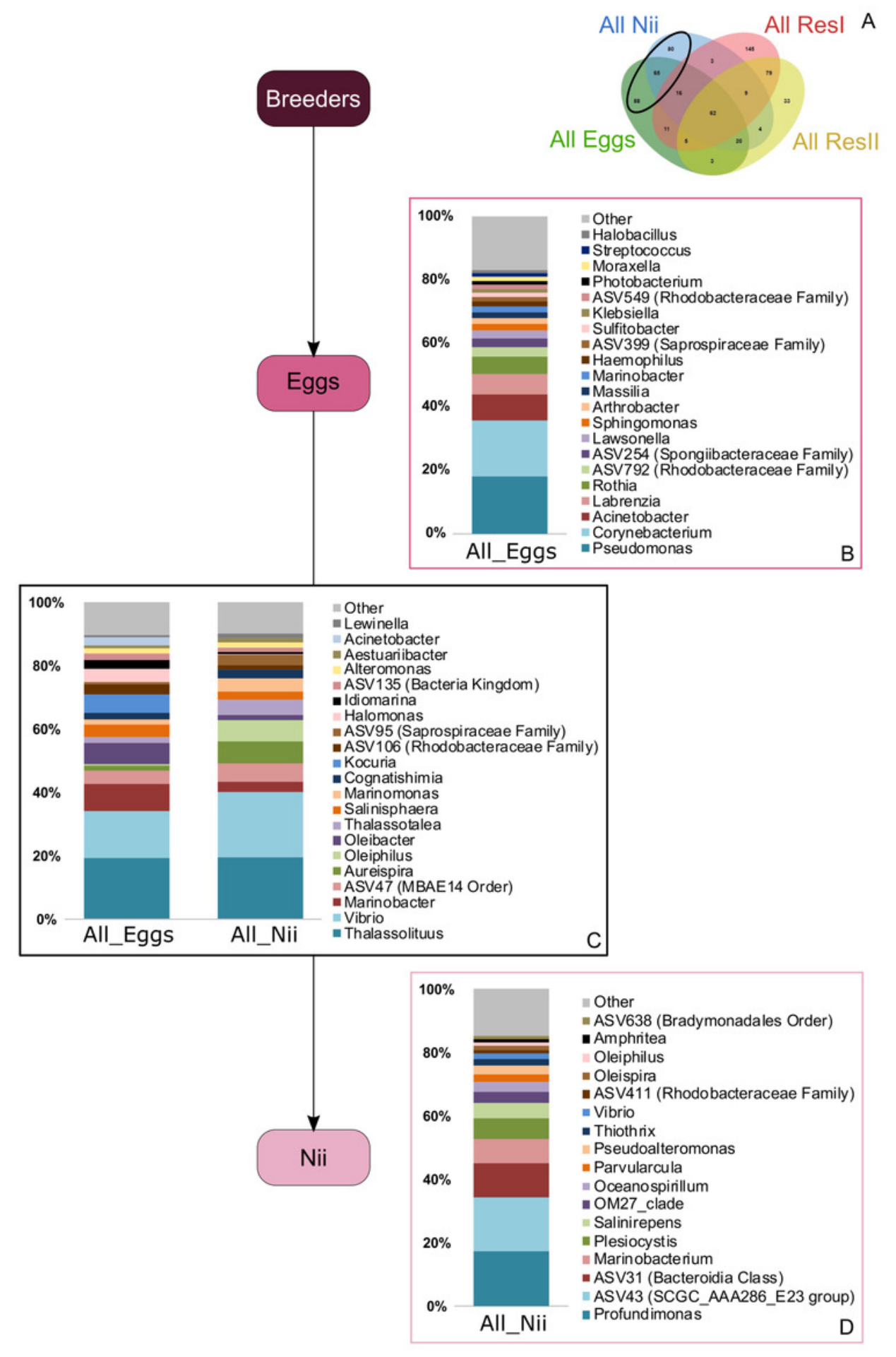


Figure 6

Schematic representation of potential microbial transmission and expression throughout the lifecycle of Litopenaeus stylirostris.

The arrows represent potential lineage transmissions.

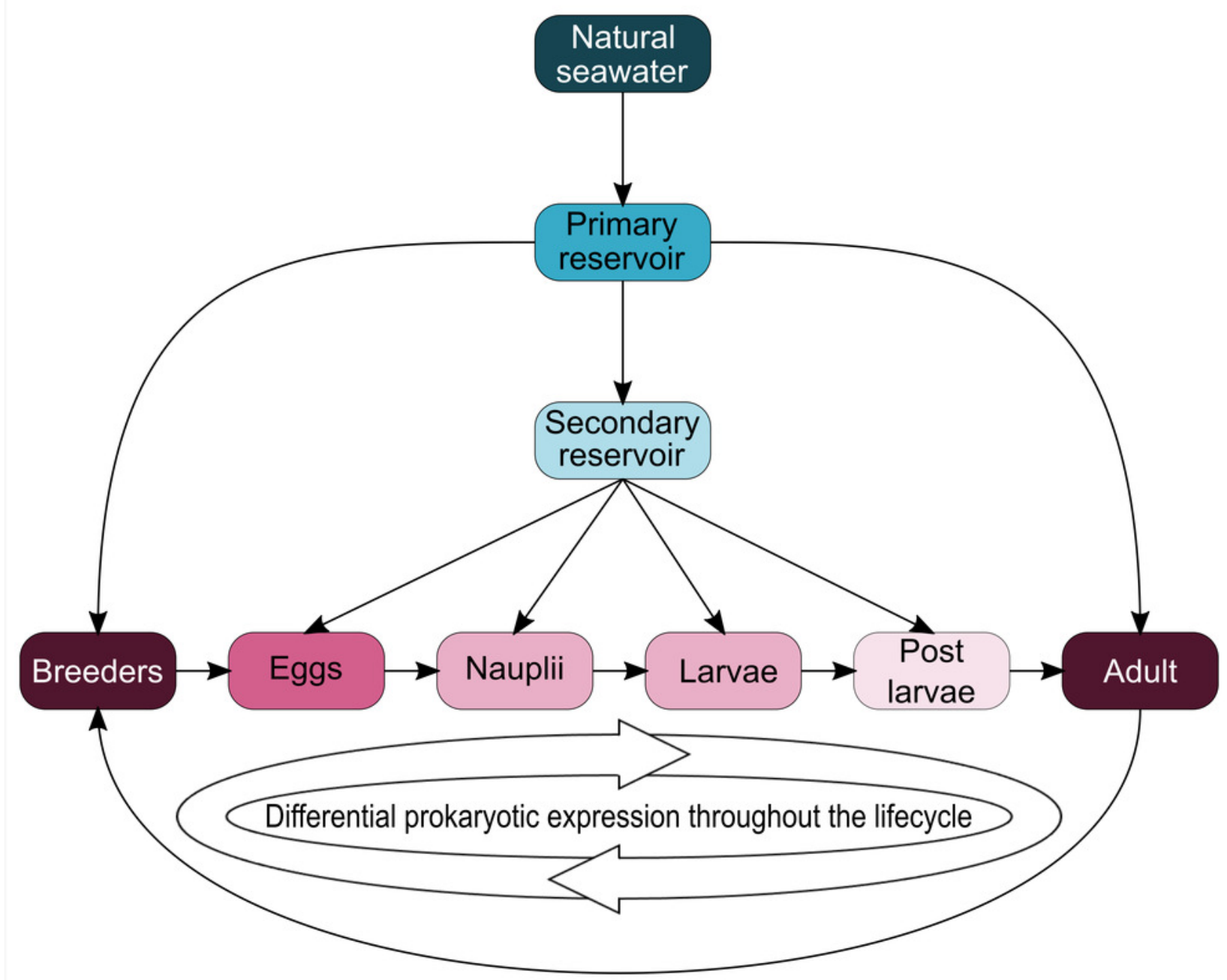

